\title{
Religiosidade popular na perspectiva da Educação Popular e Saúde: um estudo sobre pesquisas empíricas
}

\author{
Nenhuma poesia sobre o povo é autêntica se a \\ fadiga não estiver presente nela, assim como a \\ fome e a sede nascidas da fadiga. \\ Simone Weil. A mística do trabalho
}

\author{
DOI: 10.3395/reciis.v4i3.388pt
}

\section{Carla Moura Lima}

Doutoranda em Ensino em Biociências e Saúde do Instituto Oswaldo Cruz da Fundação Oswaldo Cruz IOC/Fiocruz. Rio de Janeiro, Brasil.

carlamoura@ioc.fiocruz.br

\section{Eduardo Stotz}

Sociólogo; pesquisador e professor do Departamento de Endemias da Escola Nacional de Saúde Pública Sergio Arouca, Fundação Oswaldo Cruz - ENSP/ Fiocruz. Rio de Janeiro, Brasil. stotz@ensp.fiocruz.br

\begin{abstract}
Resumo
O presente texto analisa estudos sobre Religiosidade Popular e Saúde realizados no interior da linha de pesquisa Educação, Saúde e Cidadania, cadastrada como grupo de pesquisa no CNPq. A metodologia empregada no atual trabalho utiliza elementos da revisão sistemática. Foram selecionadas duas experiências consideradas relevantes na trajetória do estudo da Religiosidade Popular, na perspectiva da Educação Popular em Saúde. Uma constatação comum a esses estudos é a de que a população, mesmo por meio da adesão religiosa, acessa e elabora dimensões do viver em localidades pobres sob o domínio de grupos violentos, aumentando sua resistência às adversidades, às iniquidades sociais e trazendo mais sentido e contentamento à vida.
\end{abstract}

Palavras-chave

religiosidade popular; educação popular; educação popular e saúde; apoio social; sofrimento difuso
O presente texto analisa estudos sobre Religiosidade Popular e Saúde realizados na linha de pesquisa "Educação, Saúde e Cidadania", e uma das vertentes do campo da Educação Popular e Saúde (EPS), organizado por pesquisadores e profissionais de saúde de diversas universidades e unidades de saúde do Brasil. Este trabalho pretende identificar, nos caminhos percorridos, trilhas e descobertas nessa trajetória iniciada há quase duas décadas.

A relação da Religiosidade Popular com a saúde ainda é pouco explorada nos meios acadêmicos, tendo destaque nas ciências humanas estudos nos campos da antropologia e da sociologia. Na área da saúde, as propostas do Prof.
Victor Valla conferiram vigoroso impulso ao interesse pela temática, na busca do entendimento de formas emergentes de organização popular (FLEURI, 2009).

Com o olhar direcionado pela perspectiva da EPS, o grupo, coordenado pelo Prof. Victor Valla, pôs como foco de seus estudos e pesquisas a Religiosidade Popular e sua relação com a saúde. Esse interesse pode ser entendido na perspectiva de que além de constituir o núcleo da cultura popular e, portanto, numa releitura de Marx, constituir a possibilidade de um protesto contra a injustiça e a opressão, a religiosidade popular apresentava-se, para Victor Valla na segunda metade da década de 1990, como um fenômeno 
político, historicamente determinado, cujos significados escapavam à compreensão dos intérpretes, os pesquisadores científicos, principalmente dos campos da educação e saúde.

A novidade que se apresentava era o fenômeno observado de crescimento acelerado, nesses anos, do pentecostalismo ${ }^{1}$ e neopentecostalismo ${ }^{2}$ entre as camadas mais miseráveis das classes trabalhadoras, por meio da conversão dos católicos, umbandistas e espíritas a diferentes denominações evangélicas que passaram a se proliferar nas periferias urbanas das grandes cidades com elevados níveis de adesão. Poder-se-ia entender esse fenômeno como uma resposta ao agravamento da situação de pobreza e de violência social acarretado pelo ajuste neoliberal dos governos de Fernando Collor e Fernando Henrique Cardoso. Mas estacionar nesse nível do entendimento significava permanecer no plano da determinação econômico-social, sem a mediação da dimensão religiosa. Assim, a pergunta a ser respondida era a de saber, nesse contexto, as razões da identidade popular com o neopentecostalismo.

O caráter massivo das manifestações religiosas sob liderança dos evangélicos e a manipulação dos sentimentos populares de contato com o sagrado ("milagres") eram, para Valla, aspectos do fenômeno, vias de aproximação da essência ou da sua compreensão e explicação.

Entre os pesquisadores a preocupação em destacar a manipulação, - dos adeptos por parte de líderes religiosos, como dimensão exclusiva do fenômeno da conversão religiosa massiva, projetou lideranças e instituições religiosas no protagonismo da organização de comunidades de fiéis e ajudou a esclarecer o surgimento e o crescimento de uma corrente política eleita pelo voto dos "crentes", hoje consolidada do ponto de vista da institucionalidade e da cultura política brasileiras.

Essa ênfase nos aspectos mercantis, financeiro e eleitoral, deixou na obscuridade o processo tal como vivido e interpretado pelas próprias classes populares. Para entender os sentidos do processo de conversão religiosa em massa do ponto de vista popular, seria necessário entender "o estreito caminho" em que sempre se moveram os mais pobres. Numa sociedade em que a identidade social passa pela capacidade de aquisição e exibição de bens de consumo, como lidar com uma situação de pobreza crônica? A drogadicção (alcoolismo, consumo de drogas ilícitas) e a marginalização no crime passaram a compensar a incapacidade de "ser igual" aos outros, destruindo jovens e famílias. Diante da miséria cotidiana sem perspectivas de melhoria, observou ele, o neopentecostalismo ofereceu mais do que um consolo ou um refúgio no misticismo. A conversão religiosa permitiu que o sentimento de impotência se transformasse "num sentimento de superioridade espiritual, de vencedor num mundo hostil" (VALLA, 1995)

Esses sentidos escapavam aos pesquisadores científicos, principalmente dos campos da educação e da saúde, dependentes de um conhecimento produzido sobre as classes populares baseado na ideia da sociedade e da política como representação. A incapacidade relativa de fazer uma investigação científica na perspectiva popular (CORRAGIO, 1989) foi denominada por Valla, em releitura de José de Souza Martins, de crise de compreensão (VALLA, 1994). Para superá-la era necessário voltar a estudar, mas com metodologias capazes de incorporar o modo como as pessoas das classes populares elaboram seu conhecimento do mundo, com toda a ambiguidade implicada pela situação de opressão e medo em que se encontram cotidianamente.

Um dos fatos desencadeadores do enveredamento por esse novo rumo na Linha de Pesquisa foi a percepção da importância crescente da Religiosidade Popular, durante os levantamentos para a elaboração do Catálogo de Iniciativas Sociais (1999), que demonstrou a crescente adesão religiosa dos moradores das favelas da região pesquisada: a Zona da Leopoldina. Essa constatação se confirmou durante a realização de pesquisas e trabalhos de assessoria a movimentos e grupos populares, na perspectiva da Educação Popular e Saúde (EPS). Neste mesmo ano, - 1999, o Cepel viabilizou a formação da Rede de Solidariedade da Leopoldina. Os participantes da Rede se reuniram na Fiocruz, para discutir questões relativas às condições de vida e saúde da região com profissionais de saúde e pesquisadores (STOTZ et al., 2009). Em paralelo, tais pesquisadores observaram certa perplexidade dos profissionais de saúde em lidar com a religiosidade dos usuários na sua prática cotidiana de Educação em Saúde e mesmo na prática clínica, cuja resolutividade passa também pela adesão da pessoa ao tratamento proposto. A partir de tais constatações identificou-se a necessidade da emergência de pesquisas que procurassem entender o significado desse movimento no tocante à saúde dessas pessoas e ao seu modo de viver.

Este esforço é parte integrante de uma opção de Victor Valla que se relaciona com a perspectiva da Educação Popular e Saúde, em especial quando proposta a partir de um lugar que se situa entre "a academia e a rua", sintetizada como busca de:

práticas de alargamento e recriação de campos de interlocução envolvendo a participação em espaços não polarizados pelas regras, valores e formas de prestígio acadêmico, a reconstrução de modos de ver 
e de ouvir o que não se conhece e a busca de modos de falar e escrever que não circunscrevam a produção cientifica a um campo de iniciados (ALGEBAILE, 2009).

\section{Alguns conceitos que perpassam todos os estudos}

No intuito de facilitar a compreensão desta perspectiva que subjaz os trabalhos relativos à Religiosidade Popular em Saúde, são apresentados alguns conceitos que os perpassam. Além deles, alguns conceitos foram cunhados no interior da Linha de Pesquisa "Educação, Saúde e Cidadania". Estes conceitos embasam todos os estudos dos pesquisadores, como também constituem patrimônio repassado para orientandos e colaboradores do trabalho. Objetivando evitar repetições e orientar a compreensão do trabalho, dentre eles destacamos: a Educação Popular e (em) Saúde; a Religiosidade Popular e Saúde; a Construção Compartilhada do Conhecimento, o Sofrimento Difuso e o Apoio Social.

\section{A Educação Popular e (em) Saúde}

O movimento da EPS se constituiu no início da década de 1990 e se rearticulou no final desta década com características de movimento social. A EPS organiza-se por meio de uma rede virtual de discussões, com encontros presenciais específicos, além de utilizar espaços oferecidos em diversos eventos da área da saúde. Também faz parte do movimento a produção de material bibliográfico.

Segundo Marteleto et al. (2003), essa diversidade de iniciativas vieram a formular certos princípios e práticas comuns ou semelhantes que configuram uma nova maneira de prestação de serviços de saúde pública, e de relação entre os profissionais e a população, o que representa uma ruptura com a tradição autoritária e normatizadora da educação em saúde (MARTELETO et al., 2003).

Esses princípios e práticas constituíram-se na Educação Popular e (em) Saúde foram entendidos pelos seus próprios participantes como

um 'movimento social' singular, composto de pesquisadores, profissionais e técnicos do chamado setor saúde, e de ativistas, técnicos e lideranças dos movimentos e organizações sociais comprometidos em participar e ampliar os esforços de emancipação das camadas trabalhadoras do povo brasileiro (STOTZ, 2005).

A proposta da EPS baseia-se na configuração de práticas de participação popular que contribuam também para a democratização do acesso ao conhecimento e à aproximação da ciência ao cotidiano das pessoas. É importante destacar que a EPS carrega em si uma complexidade de relações em que estão presentes formas discursivas diversas $e_{\text {, }}$ muitas vezes, conflitantes entre si, numa arena de disputas simbólicas, "por meio das quais revela-se a polifonia de vozes do Estado, da ciência, do mercado, das entidades civis, dos grupos comunitários, das lideranças dos movimentos sociais" (MARTELETO et al., 2003). Esta polifonia, revelada por meio de processos dialógicos, pode contribuir para aproximar a atenção nos serviços públicos de saúde da resolutividade das queixas dos usuários.

\section{Religiosidade Popular e Saúde}

A definição de Religiosidade Popular parece tão multifacetada quanto suas manifestações. Em termos gerais podemos dizer que se trata de um conjunto composto por ressignificações de crenças e ritos das religiões oficiais, tendo incorporado elementos de tradições de ancestrais constituintes da cultura local; no caso brasileiro, identifica-se na composição elementos das culturas indígenas e africanas. Um modo próprio de se relacionar com signos próprios das principais religiões, à luz das necessidades e compreensão daqueles cuja insegurança e o temor fazem parte do cotidiano. O reinventar de relações com símbolos, personagens e com o próprio Deus torna-se fundamental para aproximar tais elementos religiosos da necessidade de alimentar a própria fé, por uma questão de sobrevivência de gente "que vai em frente sem nem ter com quem contar"3 e pode dizer que "se há sorte, eu não sei, nunca vi"'.4.

Uma possível definição de religiosidade seria a forma mais utilizada pela população para expressar e elaborar a integração das dimensões racional, emocional, sensitiva e intuitiva ou a articulação das dimensões conscientes e inconscientes de sua subjetividade e de seu imaginário coletivo.

Culturalmente a religião popular desempenha vários papéis:

cria uma identidade mais coesa entre as classes populares; ajuda no enfrentamento das ameaças, oferecendo novas energias para a luta cotidiana pela sobrevivência e reforça uma resistência cultural, que, por si só, reforça também a busca da religião como solução. (VALLA, 2001b)

Alves (2005) relaciona como sendo da mesma natureza as fomes de religião e de arte no ser humano; e estas, complementares nas análises que cada um faz da realidade. A adesão religiosa das camadas populares parece estar se 
tornando cada vez mais importante. A observação desse fenômeno no âmbito da atuação no Cepel, por meio de estudos e assessoria a grupos populares, originou um novo campo de pesquisa no âmbito da Educação Popular e Saúde.

Como já foi dito anteriormente, as crenças religiosas têm atraído o interesse de profissionais de saúde e de educação. No entanto, não se espera que mudanças ocorram a curto prazo, pois por muitos anos em nossa sociedade a ciência tem sido colocada sempre em oposição à religião. Atualmente, esse conceito ou preconceito encontra-se em questionamento, e um caminho de convergência vem se abrindo lentamente, mais da parte de teólogos que de cientistas (PAIVA, 2005). Já existe um consenso de que ambas as áreas buscam conhecimentos, muitas vezes distintos, pois uma converge mais para o lado subjetivo e a outra para o objetivo, e não devemos ignorar que o ser humano, em sua complexidade, é constituído pelos dois lados simultaneamente.

Hoje, várias questões têm sido apontadas dentro do sistema de educação e saúde: a falta de visão do "todo"; a fragmentação do ensino, muito bem abordada nas jornadas temáticas organizadas por Edgar Morin (2002) e na religação dos saberes. Paulo Freire (1996), em sua jornada pela educação, sinalizou também questões, entre elas a necessidade de reconhecimento e assunção da identidade cultural do educando, mostrando que toda prática educativa envolve a experiência histórica, política, cultural e social do ser humano. Esses conceitos foram reforçados por Briceño-Leon (1996), nas suas sete teses a respeito da importância da participação popular nas campanhas de educação e saúde. O autor nos alerta para a necessidade de se conhecer o indivíduo como um todo, ou seja, seu contexto social, em termos de renda, emprego ou atividade lucrativa, moradia, cotidiano e de suas crenças, pois as mesmas têm uma forte influência na sua vida, muitas vezes determinando-a.

\section{Construção Compartilhada do Conhecimento}

A construção compartilhada do conhecimento é uma metodologia sistematizada no âmbito da ENSP/Fiocruz, resultante de uma investigação participativa desenvolvida pelo Núcleo de Educação, Saúde e Cidadania, no início da década de 1990. Esta metodologia também é vista como um conceito que considera a experiência cotidiana dos atores envolvidos em práticas de educação e saúde e tem por finalidade a conquista, pelos indivíduos e grupos populares, de maior poder e intervenção nas relações sociais que influenciam a qualidade de suas vidas. Esta proposta implica um processo comunicacional, interativo e cooperativo e intencionalmente pedagógico, entre "pessoas ou grupos com experiências diversas, interesses, desejos, motivações coletivas" (CARVALHO et. al., 2001).

Os princípios da construção compartilhada do conhecimento estão fundamentados na Educação Popular e a referência para o conceito de aprendizagem vem do construtivismo, que concebe o sujeito como o construtor do conhecimento, na medida em que observa, analisa as experiências de forma particular, buscando compreender o mundo. A pedagogia problematizadora se constitui numa matriz do ponto de vista metodológico, que critica práticas educativas centradas na transmissão de conhecimento (CARVALHO, 2007), o que Paulo Freire chamou de "educação bancária" (FREIRE, 1987).

Carvalho (2007) identifica como princípios da construção compartilhada do conhecimento em práticas educativas: trabalhar as questões a partir do interesse e visão de mundo dos grupos envolvidos; promover uma relação de diálogo, de escuta, processos de construção de conceitos, valores e posturas, cooperação e possibilitar extrema liberdade nas ações educativas; problematizar a realidade local; estimular a prática metodológica dialética, a interação entre os sujeitos, processos construtores de autonomia; utilizar múltiplas linguagens como instrumentos metodológicos; manter uma postura investigativa da realidade, articulando o processo de ação-reflexão-ação (CARVALHO, 2007).

Marteleto et al. (2003) destacam ainda que, para o conhecimento produzir sentido e orientar decisões e ações no campo das questões da saúde da população, é importante fundar e organizar processos de construção compartilhada do conhecimento (CARVALHO, 2007), da qual pode derivar um "terceiro conhecimento" derivado das diferentes combinações, provisórias e renováveis, entre conhecimento científico (ou informacional) e o conhecimento popular (ou prático) (MARTELETO, 2001).

\section{Sofrimento Difuso}

Frente à atual conjuntura de precariedade da oferta de oportunidades de geração de renda e da fragilidade das relações sociais, cada vez mais pessoas vêm manifestando sinais de adoecimento (LIMA, 2006) que se expressam por meio de queixas somáticas inespecíficas, tais como dores de cabeça e no corpo, insônia, nervosismo, problemas gástricos e estados de mal-estar não classificáveis nos diagnósticos médicos ou psiquiátricos (FONSECA et al., 2008). Os profissionais de saúde, de modo geral, não estão preparados para lidar com esta demanda e tendem a identificar essas pessoas como "pacientes poliqueixosos" ou "pitiáticos" (SAVI et al., 2009). 
As causas dessas queixas podem ser multideterminadas, tendo em vista o contexto social no qual as pessoas que utilizam os serviços públicos de saúde estão inseridas (VALLA, 1999, 2001). Pesquisas apontam que, em média, $60 \%$ das pessoas atendidas em unidades de saúde da rede pública apresentam essas queixas, cuja solução requer mais tempo, recursos e talvez paradigmas mais abrangentes de entendimento do processo saúde-doença e sua relação com as condições de vida das pessoas (LIMA et al., 2003, 2005). Embora o sofrimento desses pacientes seja relativizado por alguns profissionais de saúde, por não haver evidências de uma doença (LACERDA, 2002), essas questões são apontadas por alguns autores como relevantes para a saúde pública (VALLA, 1998). Parte considerável dos profissionais de saúde costuma classificar essa clientela como pacientes poliqueixosos, psicossomáticos, funcionais, psicofuncionais, histéricos, pitiáticos. A reflexão sobre as queixas somáticas inespecíficas é relevante para os profissionais da atenção básica, na medida em que pode ampliar a compreensão a respeito dos usuários do sistema de saúde que demandam por atenção sem portar necessariamente nenhuma doença enquadrada em manuais diagnósticos. Tirar esses usuários de categorias pré-estabelecidas ou preconceituosas e perceber suas necessidades de cuidado e acolhimento é um grande desafio para os profissionais da ponta, assim como para seus processos de trabalho (FONSECA, 2008).

\section{Apoio Social}

A teoria do apoio social se tornou uma importante referência para os estudos de religiosidade popular e saúde, na tentativa de entender formas emergentes de organização popular. Valla (1999b) relacionou o início das discussões sobre apoio social (social support) com um debate da saúde pública nos Estados Unidos na década de 80 e propôs uma releitura do termo à luz da realidade brasileira. $\mathrm{O}$ autor define apoio social como sendo "qualquer informação falada ou não e/ou auxílio material oferecidos por grupos ou pessoas que se conhecem e que resultam em efeitos emocionais e/ou comportamentos positivos" (VALLA, 1999b).

Esse apoio, normalmente, se passa entre pessoas que se conhecem e se encontram de forma sistemática, razão pela qual geralmente se dá em torno da frequência a alguma instituição (LACERDA et al., 2002). No contexto brasileiro essa teoria abarcaria soluções encontradas para o estado de "estresse contínuo" no qual se encontram as camadas populares que estão expostas ao que Valla et al. (1999) chamaram de "estado de emergência permanente".
Segundo a teoria do apoio social, o apoio material, emocional e de informação prestado às pessoas, de uma forma sistemática, exerce um efeito positivo sobre a saúde delas (LACERDA et al., 2003). É o caso do atendimento prestado pelas instituições religiosas.

Uma das explicações possíveis para o ingresso e permanência das camadas populares nas igrejas evangélicas é a teoria do apoio social, que relaciona a origem das doenças com as emoções, apontando que a solução dos problemas de saúde estaria relacionada com as mesmas. Sua proposta central é a de que quando se conta com o apoio de um grupo de pessoas, esse apoio tem o efeito de causar melhora na saúde das pessoas envolvidas.

\section{Metodologia}

A metodologia empregada no presente trabalho utiliza elementos da revisão sistemática que se baseia em estudos primários, utilizando métodos previamente definidos e explícitos para identificar, selecionar e avaliar criticamente pesquisas consideradas relevantes (ARAÚJO, 2008). No nosso caso, foram selecionadas duas experiências consideradas relevantes na trajetória do estudo da Religiosidade Popular na perspectiva da Educação Popular em Saúde, realizadas na linha de pesquisa "Educação, Saúde e Cidadania". A primeira foi a pesquisa "Situação de Pobreza e Saúde: a busca de recursos pela população na periferia do município do Rio de Janeiro" (1999/2002); a segunda foi a pesquisa "Religiosidade, Sociedade Civil e Saúde: um estudo sobre redes e apoio social no cuidado integral à saúde" (2007).

\section{Resultados e discussão}

Neste momento são apresentados resultados e discussões dos dois estudos selecionados. Ao final da sessão, uma tabela apresenta tais estudos, de forma mais sintética (Tabela 1).

Estudo 1 - Pesquisa "Situação de Pobreza e Saúde: a busca de recursos pela população na periferia do município do Rio de Janeiro"

Lima et al. (2005) analisaram aspectos desta pesquisa iniciada no fim de 1999, a partir de um levantamento que objetivou a elaboração de um catálogo de iniciativas sociais na Leopoldina, e foi concluída em 2003. A zona da Leopoldina ocupa uma área que abrange em torno de 10\% da cidade do Rio de Janeiro. Conhecida como uma das mais violentas, abriga quatro complexos de favelas: Maré, Manguinhos, Alemão e Penha, além da comunidade de 
Vigário Geral. Durante o mapeamento das iniciativas sociais, notou-se uma grande quantidade de instituições religiosas que desenvolviam algum tipo de assistência à população, muitas vezes exercendo papéis inerentes ao Estado que, historicamente, se ausenta de comunidades de baixa renda, como as favelas da Leopoldina.

Uma questão colocada desde o início consistia em saber se as pessoas que frequentam instituições religiosas estão preferindo outras formas de se organizarem para lutar pela vida, diferente da participação política mais tradicionalmente conhecida como o engajamento em associações de moradores e em partidos políticos, por exemplo. A pesquisa visou também compreender porque a participação em instituições religiosas tem crescido tanto nestas comunidades e bairros populares.

Uma hipótese inicial da pesquisa era a de que os problemas relacionados com o acesso e a resolutividade do sistema público de saúde contribuem para que uma parcela significativa das camadas populares procure alívio para seus sofrimentos no campo religioso. Diante dos diferentes impasses, observaram-se diferentes respostas congruentes: consumismo, violência ativa ou passiva, uso de drogas e adesões religiosas ou adoecimento físico. No caso das adesões religiosas, imaginava-se que seu crescimento acompanhava o aumento dos impasses identificados na vida cotidiana das classes populares que vivem em contextos de pobreza e violências. Tais impasses podem ser exemplificados como: a busca de atendimento médico em dificuldade de resolutividade dos tratamentos tendo em vista a pobreza; as limitações ao exercício de direitos básicos como liberdade de ir e vir, à fala, ao acesso ao Poder Judiciário, aos serviços públicos de qualidade, enfim, à dignidade.

O principal objetivo da pesquisa, segundo Lima et al. (2003), foi fomentar o debate sobre a importância da religiosidade na vida e na saúde das camadas populares entre diversos segmentos da sociedade, como profissionais de saúde e de educação que trabalham diretamente com essa população, lideranças religiosas da região, grupos organizados, lideranças locais, lideranças de esquerda da classe média (que geralmente olham a questão com desconfiança e reserva).

E, por outro lado, foi se confirmando a necessidade de a pesquisa contribuir para a compreensão dos profissionais de saúde a respeito dos itinerários terapêuticos percorridos pelos usuários do Sistema Único de Saúde (SUS). Refletindo acerca dos preconceitos observados na classe média, à qual pertence a maioria dos profissionais, sobre a ida dos usuários às igrejas, foi possível abrir a percepção de que as iniciativas da população podem indicar caminhos possíveis e eficazes, sem a necessidade de utilização de muitos recursos financeiros, para a implementação de políticas públicas em saúde.

Durante a trajetória da pesquisa tornou-se pouco provável a concepção de que as chamadas curas milagrosas (em geral espetaculares) ocorridas com os frequentadores seriam o principal fator de atração e de permanência nas igrejas. A maioria não pareceu ser contemplada com curas milagrosas. Mas a sua permanência nessas igrejas indica que essa frequência de alguma forma gera resultados benéficos à saúde das pessoas. Os ambientes observados nas igrejas pentecostais e neopentecostais exalam entusiasmo desde a entrada - com recepcionistas sorridentes, apertando as mãos de quem chega, e canções cujos ritmos e conteúdos das letras procuram incentivar os presentes a confiar em Deus e em si mesmos, já que são considerados Sua imagem e semelhança.

Parker (1996) sugere que, para um entendimento da religiosidade popular manifestada pelas classes populares, é importante que haja uma reinterpretação do processo de modernização da América Latina. Este autor lembra que a religião faz parte da cultura popular, portanto as pessoas nascem dentro de uma cultura que já é religiosa. Onde a perspectiva religiosa está profundamente inserida no seu cotidiano. A população, que em geral é católica, mesmo não frequentando a igreja mantém a noção de que pode haver soluções dentro dessa perspectiva, o que explica a procura por instituições religiosas como uma alternativa à qual as camadas populares recorrem.

Todos os entrevistados reconhecem que a busca às instituições religiosas se dá principalmente em função das precárias condições de vida das classes populares como: desemprego, doenças e desestrutura familiar. A perspectiva de salvação e habitação no céu após a morte não parece ser fator de atração de fiéis. Cesar e Shaull (1999) trabalham com a tese de que a experiência religiosa é feita na vida cotidiana de pessoas que não têm nenhum projeto, pois a vida não reserva nada para elas.

Bonfatti (2000) observou que é lugar-comum na igreja a importância do simples escutar. O autor assinala que, por meio da psicologia, é conhecido que este simples componente na relação de ajuda processa resultados quase imediatos na pessoa escutada.

Machado (1996) desenvolveu sua investigação basicamente em torno de duas hipóteses. A primeira hipótese é a de que "as consequências da adesão religiosa nas relações familiares são diferenciadas, caso o converso 
seja homem ou mulher". A segunda é a de que as mulheres, ao aderirem ao pentecostalismo, tendem a reproduzir o padrão patriarcal. Já as conversões masculinas tendem para o desenvolvimento de relações mais simétricas entre os gêneros, decorrentes da mudança radical do estilo de vida, que termina por contemplar mais os interesses da mulher e dos filhos.

Corten (1996) afirma que o pentecostalismo se caracteriza pela importância dada à emoção. Segundo Valla (2002) a grande contradição, para muitos observadores de classe média, é que se trata de pessoas que frequentemente vivem na pobreza, na doença e em ambientes repletos de violência, e, no entanto, experimentam essa intensa alegria de estarem vivas." Acompanhando os cultos de Libertação, numa igreja neopentecostal, essa alegria era observada nos fiéis e confirmada através de conversas informais, nas quais relatos de cura de estados denominados depressivos pelos fiéis foram relatadas.

Durante a pesquisa, a noção de que as pessoas estavam optando pela frequência às igrejas, a despeito da participação político-comuntária, não se confirmou. Foram encontrados casos de lideranças religiosas que afirmaram terem iniciado a militância em projetos comunitários após sua conversão ao cristianismo pentecostal ou neopentescostal. O abandono do consumo de drogas, bebidas alcoólicas e as farras com mulheres, aliados à elevação da autoestima propiciaram o vislumbre de novos horizontes para si e para suas comunidades. A autoconfiança e a crença de ter sido escolhido e estar sendo "capacitado" por Deus aparecem como forças propulsoras, que impulsionam para um protagonismo inédito no âmbito individual, coletivo e comunitário.

Não se trata aqui de ignorar a existência de pastores que conduzem suas atividades voltadas para o enriquecimento pessoal através da oferta dos fiéis. Trata-se de reconhecer que a maioria das igrejas encontradas na região pesquisada são dirigidas por pessoas simples que se preocupam com a situação das comunidades. Muitos demonstram disposição em fazer o possível para contribuir em prol da melhoria da situação daqueles que sofrem. Sofrem porque ainda são analfabetos, com a falta de ocupação para os jovens em situação de risco social, com pessoas que moram em condições muito precárias e tantas outras dificuldades enfrentadas pelas classes populares.

Lideranças religiosas de uma denominação protestante histórica, que está situada numa das mais violentas comunidades da Leopoldina, embora acreditassem que há doenças de origem espiritual, atribuem ao desemprego a origem da maioria das doenças. E a entrada para o narcotráfico como consequência das condições de vida das pessoas. E veem como papel da igreja lutar por condições de vida mais dignas para a população.

Embora haja outros espaços coletivos onde as pessoas possam "aliviar as tensões do dia-a-dia", as igrejas evangélicas, localizadas em comunidades e bairros como os da zona da Leopoldina, têm-se mostrado um locus privilegiado para as classes populares. Os resultados parecem indicar que, para a população de estratos socioeconômicos mais baixos, as instituições onde predomina o saber oficial em saúde ainda estão longe de oferecer, no geral, espaços de interlocução para demandas subjetivas. Isto pode demonstrar que mesmo cosmovisões mais includentes, como as cristãs pentecostais, permeadas de experiências de cura e estabelecimento de sensações de bem-estar físico e emocional e um sentimento de pertencimento, por vezes inéditos, também não se mostraram suficientes para a satisfação de todas as necessidades em saúde dos frequentadores - o que não impede que autores denominem essas instituições religiosas como equipamentos de Saúde Pública e classificassem cultos religiosos como agências terapêuticas (RABELO, 1993).

A principal razão da pesquisa foi contribuir para o entendimento mútuo - entre técnicos (profissionais de saúde e educação), pesquisadores e as classes populares para que, juntos, efetivamente pudessem encontrar alternativas para esse estado de pobreza e desemprego que tanto atinge a maioria. Tais pesquisas pretendem contribuir para a compreensão da lógica presente no falar e no fazer das classes populares, diminuindo assim o fosso existente entre a ação dos serviços públicos de saúde e a ação popular na luta contra doenças, principalmente as crônicas (VASCONCELLOS, 1998).

Entendeu-se também que alternativas encontradas pela população podem indicar caminhos possíveis, que não exijam muitos recursos financeiros para o estabelecimento de políticas públicas que realmente venham ao encontro do que as classes populares precisam e lhes é de direito.

Estudo 2 - Pesquisa Religiosidade, Sociedade Civil e Saúde: um estudo sobre redes e apoio social no cuidado integral à saúde

Lacerda et al. (2008) analisaram a adesão religiosa de agentes comunitários de saúde (ACS) frequentadores das rodas de Terapia Comunitária, pois estes demonstravam mais resistência às adversidades da sua vida pessoal e profissional.

A Terapia Comunitária é uma técnica grupal que se constitui em uma prática de cuidado em saúde que lida com o sofrimento humano e o terapeuta comunitário atua como um mediador 
que procura estimular e favorecer a partilha de experiências, possibilitando a construção de redes de apoio social.

Algumas pesquisadoras da Escola Nacional de Saúde Pública Sérgio Arouca criaram grupos de Terapia Comunitária com os ACS, de modo que esses trabalhadores pudessem partilhar suas experiências de vida com o intuito de potencializar recursos individuais e coletivos que os auxiliassem a encontrar possíveis caminhos para resolução dos problemas levantados.

Os grupos de Terapia Comunitária com os ACS propiciaram um contato mais próximo dos pesquisadores com esses agentes de saúde, e a constatação de que muitos deles pertenciam às igrejas pentecostais e neopentecostais. Com isto entendeu-se ser relevante discutir a inserção religiosa desses trabalhadores e o impacto no seu processo de trabalho.

Foi nessa perspectiva que se realizou uma pesquisa empírica de caráter qualitativo, com entrevistas abertas porém, com alguns conteúdos temáticos, de tal modo que a entrevistada pôde discorrer livremente acerca das questões propostas pelo pesquisador. Optou-se por utilizar esse tipo de entrevista pois, de acordo com Montenegro (1992), possibilita ao entrevistado um extenso campo de estímulos capazes de desencadear processos involuntários de associação e de rememoração. Nesse sentido, foi estabelecida uma relação dialógica entre entrevistado e entrevistador, respeitando-se os diferentes saberes (MARTINS, 1989).

Foram entrevistados sete ACS moradores e trabalhadores de centros de saúde de comunidades do complexo da Maré, na região da Leopoldina, sendo seis do sexo feminino e um do sexo masculino, todos pertencentes a igrejas pentecostais e neopentecostais.

Interessava conhecer a motivação da busca e da adesão religiosas. A filiação dos sujeitos às igrejas pentecostais e neopentecostais em momentos difíceis de vida se confirmou na pesquisa. A adesão religiosa dos ACS entrevistados foi motivada por diversas circunstâncias. Alguns frequentavam as igrejas evangélicas desde criança por influência da própria família mas, em geral, o que observamos é que o momento que antecede à adesão costuma ser precedido por uma situação de crise, um tipo de sofrimento e aflição relatado como uma sensação de vazio existencial ou como se estivessem no "fundo do poço", seja em função das precárias condições de vida; de problemas de saúde na família; de alcoolismo e uso de drogas; de envolvimento de entes queridos no tráfico de drogas e outras atividades ilícitas.

Como resultado da pesquisa, destaca-se a constatação do fortalecimento dos laços sociais. Alguns ACS falaram das amizades conquistadas e dos vínculos de confiança estabelecidos com outros membros da igreja. Nas igrejas construíram-se relações de solidariedade ao compartilhar problemas semelhantes. A fé é um valor importante para esses fiéis, e pode ser visto como um dos bens intangíveis circulantes nas redes sociais e que norteia a busca por cuidado à saúde. A partir da adesão, os fiéis passaram a perceber e a ressignificar as situações vivenciadas de uma maneira própria. Por meio de códigos compartilhados entre si e do sentimento de pertencimento, o trabalho dos ACS também passou a ter um novo significado. Compreendeu-se dessa forma que o trabalho, como parte intrínseca da vida desses ACS, também assume uma esfera sagrada e sobrenatural.

Para os ACS entrevistados, a realização de um preparo espiritual, por meio da oração, antes de sair para o trabalho, torna-se pré-condição que visa a garantir um bom desempenho profissional, pois têm consciência de que lidam com diferentes sujeitos e seus sofrimentos. Os ACS se sentiam mais fortalecidos por meio da frequência a cultos religiosos e das orações, o que Ihes permitia sentirem-se mais preparados para lidar com a diversidade e complexidade do seu trabalho.

Apesar de alguns técnicos expressarem a preocupação com o fato de os ACS serem evangélicas pentecostais e neopentecostais, entendendo que a adesão a essas religiões poderia trazer problemas no lidar com a população - como, por exemplo, a recusa a visitar as casas de famílias que são centros de umbanda ou de candomblé - observou-se, nesse grupo de entrevistados, que esse pensamento não procede.

Os ACS evangélicos distinguem a doença do corpo, ou seja, material, da doença da alma, de natureza espiritual, e o seu olhar nas visitas domiciliares pareceu imbuído dessas representações sobre a saúde e a doença. Elas entenderam que as doenças do corpo físico também podiam ser causadas por problemas de outras ordens - psicológicas ou espirituais - e, algumas vezes, recorreram a soluções que denominam de "sobrenaturais", como orações pela cura das pessoas. Expressa uma concepção popular da etiologia.

Não é recente o "desconcerto" dos profissionais de saúde diante dos aparentemente ecléticos itinerários terapêuticos dos usuários, que recorrem à biomedicina mas também a tratamentos conhecidos como espirituais. Para as camadas populares, cujas visões do processo saúde-doença podem ser identificadas como ecológicas e holísticas, o domínio sobrenatural como explicação etiológica requer a frequência a lugares de culto religioso, obrigações e práticas para a cura. Sua explicação para o processo de adoecimento é multifatorial, e o sobrenatural aparece associado a "explicações de caráter 
psicossocial e, embora se refira à esfera 'metafísica', seu lugar é o corpo" (MINAYO, 1988).

Por terem essa visão ampliada e integral do ser humano, os ACS evangélicos podem interferir no itinerário terapêutico do usuário, a partir do diálogo e de uma conduta individualizada, específica a cada encontro. Eles, em alguns casos, interferem no processo terapêutico do usuário, encorajando-o a refletir acerca de sua doença e a buscar as causas que estão ocasionando os seus problemas de saúde. Isto, em certo sentido, complementa o atendimento médico que é oferecido pelo sistema público de saúde, pois não se restringe à doença na sua dimensão física, mas busca uma atenção integral de acordo com as necessidades de cada morador visitado. Constroem, assim, um projeto terapêutico junto com o usuário voltado para atender as demandas de saúde colocadas por sua clientela, e sintonizado com o contexto específico de cada encontro e de cada sujeito (MATTOS, 2004).

Alia-se a isso o fato de que, em geral, a visão religiosa - pentecostal e neopentecostal, especialmente - inserese em uma perspectiva otimista da vida, onde os fiéis são encorajados a ter controle sobre as suas vidas e a buscar a solução dos problemas.
A adesão religiosa dos ACS foi entendida como uma estratégia de enfrentamento dos problemas de saúde e das adversidades da vida, tendo em vista que as classes populares vivem em estado de emergência permanente (VALLA et al, 2005). Ao compartilhá-la com outros cristãos, os ACS se sentem cuidados e fortalecidos para exercerem o seu trabalho.

Há algumas iniciativas que colocam em diálogo direto o campo técnico-científico e o religioso nos serviços de atenção básica, como o exemplo do trabalho das rezadeiras em unidades de saúde no estado da Paraíba (SILVA, 2004).

Segundo Brandão (2007), estudar religião talvez seja a melhor maneira de se compreender a cultura popular, pois ela "existe em franco estado de luta acesa, ora por sobrevivência, ora por autonomia, em meio a enfrentamentos profanos e sagrados entre o domínio erudito dos dominantes e o domínio popular dos subalternos" (BRANDÃO, 2007).

$\mathrm{Na}$ reorientação dos cuidados em saúde, vimos constatando que a dimensão emotiva, do afeto e do comprometimento dos agentes de saúde em relação aos problemas dos usuários tem tido mais eficácia do que a dimensão racional e lógica da palavra (VASCONCELOS, 2006). Através da compaixão sentida, da sensação da

Tabela 1 de características dos estudos sobre Religiosidade Popular

\begin{tabular}{|c|c|c|c|c|}
\hline Pesquisa/Perlodo & $\begin{array}{l}\text { Abrangência } \\
\text { geográfica }\end{array}$ & Metodologia & Alguns resultados & Conclusões \\
\hline $\begin{array}{l}\text { "Situação de } \\
\text { Pobreza e Saúde: } \\
\text { a busca de } \\
\text { recursos pela } \\
\text { população na } \\
\text { periferia do } \\
\text { município do Rio } \\
\text { de Janeiro" } \\
\text { (1999 a 2002) }\end{array}$ & $\begin{array}{l}\text { Zona da } \\
\text { Leopoldina } \\
\text { (Alemão, Penha, } \\
\text { Vila da Penha e } \\
\text { Manguinhos) }\end{array}$ & $\begin{array}{l}\text { - Observação } \\
\text { Participante } \\
\text { - Entrevistas } \\
\text { semi- } \\
\text { estruturadas }\end{array}$ & $\begin{array}{l}\text { - a noção de despolitização pós- } \\
\text { adesão religiosa não se } \\
\text { confirmou } \\
\text { - abandono do consumo de } \\
\text { drogas, bebidas alcoólicas, } \\
\text { adultério, elevação da autoestima } \\
\text { após sua conversão ao } \\
\text { cristianismo pentecostal ou } \\
\text { neopentescostal } \\
\text { - as igrejas têm se mostrado um } \\
\text { locus privilegiado para as classes } \\
\text { populares. }\end{array}$ & $\begin{array}{l}\text { - alternativas da } \\
\text { população indicam } \\
\text { caminhos para políticas } \\
\text { públicas que realmente } \\
\text { venham ao encontro do } \\
\text { que as classes populares } \\
\text { precisam e lhes é de } \\
\text { direito. }\end{array}$ \\
\hline $\begin{array}{l}\text { "Religiosidade, } \\
\text { Sociedade Civil e } \\
\text { Saúde: um estudo } \\
\text { sobre redes e } \\
\text { apoio social no } \\
\text { cuidado integral à } \\
\text { saúde" } \\
\text { (2007) }\end{array}$ & $\begin{array}{l}\text { Zona da } \\
\text { Leopoldina } \\
\text { (Complexo da } \\
\text { Maré) }\end{array}$ & $\begin{array}{l}\text { - entrevistas } \\
\text { abertas }\end{array}$ & $\begin{array}{l}\text { - A filiação dos sujeitos às igrejas } \\
\text { pentecostais e neopentecostais } \\
\text { em momentos difíceis de vida se } \\
\text { confirmou na pesquisa. } \\
\text { - O fortalecimento dos laços } \\
\text { sociais: alguns ACS falam das } \\
\text { amizades conquistadas e dos } \\
\text { vínculos de confiança } \\
\text { estabelecidos com outros } \\
\text { membros da igreja. } \\
\text { - maior proximidade com os } \\
\text { usuários, interferindo em seus } \\
\text { itinerários terapêuticos. } \\
\text { - respeito pelas outras religiões } \\
\text { de usuários. } \\
\text { - orações complementam o } \\
\text { trabalho dos ACS; }\end{array}$ & $\begin{array}{l}\text { - a dimensão emotiva, do } \\
\text { afeto e do } \\
\text { comprometimento dos } \\
\text { agentes de saúde em } \\
\text { relação aos problemas } \\
\text { dos usuários tem tido } \\
\text { mais eficácia do que a } \\
\text { dimensão racional e } \\
\text { lógica da palavra } \\
\text { - O ACS religioso, ao } \\
\text { realizar o seu trabalho, } \\
\text { possibilita a reflexão } \\
\text { acerca dos conflitos } \\
\text { morais, afetivos e } \\
\text { psicológicos que podem } \\
\text { estar na base dos seus } \\
\text { problemas de saúde. }\end{array}$ \\
\hline
\end{tabular}


presença de Deus e da fé, o crente vê a sua vida de outra maneira (CORTEN, 1996). O ACS religioso, ao realizar o seu trabalho de integralidade na atenção e cuidado à saúde dos moradores, não restringe o seu olhar aos aspectos físicos da doença, mas redimensiona-o em um novo contexto que compreende a enfermidade como uma provação que coloca ao usuário a possibilidade da reflexão acerca dos conflitos morais, afetivos e psicológicos (MARIZ, 1994), que podem estar na base dos seus problemas de saúde.

Embora tenham começado no campo da psiquiatria, estudos sobre religiosidade popular concentram-se até hoje na sociologia e na antropologia. Há uma defasagem do campo da saúde, e em especial da educação em saúde no considerar a importância de estudos sobre esse tema cada vez mais significativo para a população pobre que vive em grandes cidades (DALGALARRONDO, 2007). Essa população morre cada vez mais de doenças crônicas, e não de infectoparasitárias, quando não morre diretamente por violências morre de "susto" por conviver com elas.

Incluir a diversidade e a heterogeneidade é um dos maiores desafios atuais de todos os processos que envolvem educação, já que sua universalidade é historicamente questionada (STOTZ, 2005). Fasheh (2004) afirma a necessidade de se repensar qualquer coisa que se diz universal, compreendendo que a diversidade é elemento constituinte da natureza da vida, onde cada pessoa é uma fonte de compreensão criadora, observadora e construtora e autora de uma realidade, e, além disto, toda experiência tem um valor a ser compartilhado.

Devemos conhecer, entender, respeitar o "poder" que as religiões exercem sobre a população e abrir mão da postura - muito comum de nosso tempo, como diz Silas Guerreiro (2005) -, de acreditar que as crenças só existem porque não temos explicação para muitas coisas que acontecem na natureza. Mas é importante considerar, assim, que a ciência e a religião são dois pilares distintos do conhecimento humano, cada um abarcando uma faceta da existência humana. A partir do momento em que a ciência se abre para estudar, discutir e respeitar os fenômenos religiosos, o saber do "outro" - do próximo que, muitas vezes, é o estudante ou o que sofre e acessa o serviço público de saúde -, poderá tornar-se enriquecedora, tanto para o educando como para o profissional de saúde-educador em saúde, a abordagem de temas como clonagem, inseminação artificial, bebê de proveta, barriga de aluguel, pesquisa com células-tronco embrionárias de seres humanos, evolução e as teorias da origem da vida.

\section{Conclusão}

Uma constatação comum a esses estudos é a de que adesão religiosa da população pobre elabora dimensões de vivência que aumentam sua resistência às adversidades e às iniquidades sociais, trazendo mais sentido e contentamento à vida.

O potencial racionalizador oferecido pela adesão religiosa, e da religiosidade popular como um todo, parece ser uma das grandes forças mobilizadoras de energias de resistência e de esperança observadas em momentos diversos dos estudos, mediante procedimentos como entrevistas individuais, observação participante de cultos religiosos e fóruns de discussões coletivas.

Tal adesão é parte essencial dos esforços pela cura de enfermidades e alívio dos sofrimentos. São tentativas inerentes à natureza humana, porém tão mais difícil se torna a condição humana quanto mais pobre se é. A dor parece ser acentuada de se sofrer tanto em serviços públicos de saúde em um país que tem uma das maiores economias do mundo, mas também é um dos campeões em desigualdade social. O desespero pela cura parece ser proporcional não só ao tamanho e gravidade da enfermidade, mas ao nível de miséria em que se está mergulhado.

Os resultados de ambas pesquisas analisadas demonstraram que, por um lado, os frequentadores de igrejas pentecostais e neopentecostais, incluindo os ACS, não encontraram curas milagrosas. Por outro lado, revelaram relatos de encontro de apoio social, diminuição de queixas relacionadas ao sofrimento difuso e o encontro de "forças para continuar".

As igrejas pentecostais e neopentecostais são ambientes alegres, em geral, onde se pode dançar, cantar, bater palmas, sorrir e chorar. Para os "desfiliados" da sociedade, serem chamados de irmãos e irmãs por dezenas de pessoas que compartilham as mesmas situações sociais, muitas vezes também familiares e pessoais, pode ser um lenitivo para as suas dores. Finalmente, um sentimento de pertencimento.

A perspectiva religiosa está sempre presente no cotidiano dessas pessoas, o que torna o diálogo com os não adeptos às igrejas possível. Embora parecendo contraditório, o respeito observado entre os "não-crentes" nas comunidades, por praticantes de atos ilícitos, parece tornar essa convivência menos conflituosa. Para aqueles que reconhecem ter "uma vida torta", contar com as frequentes abordagens dos vizinhos religiosos, que demonstraram interesse pelas suas vidas, indica o não abandono e, talvez, uma possibilidade de saída. 
Nos estudos analisados, os discursos dos religiosos indicaram buscas de soluções para problemas do seu cotidiano, com destaque àqueles relacionados à própria saúde ou de familiares. Embora sejam atribuídos a causas transcendentais, a vida pós-morte parece quase não preocupar. Para essas pessoas, que frequentam igrejas e são usuárias do Sistema Único de Saúde (SUS), prevaleceu o desejo de viver e com saúde.

O SUS representa um grande avanço na tentativa de atendimento universalizado em saúde, mas ainda não consegue atender à imensa quantidade de miseráveis, além de alcançar níveis de resolutividade que ainda deixam muito a desejar. A escolha por estudar favelas da região se deu pelo fato de se considerar a Leopoldina como um microcosmo da realidade brasileira.

Na direção do aumento da resolutividade das demandas que chegam aos serviços de saúde, o estabelecimento de práticas efetivamente dialógicas pode contribuir. Trata-se de um caminho possível que depende da abertura, por parte dos profissionais, em incorporar a valorização da cultura daqueles que sofrem.

Nesse sentido, a compreensão das condições de vida da população e, em especial, do seu contexto religioso, pelos profissionais de saúde, pode ser um importante passo para lidar com desafios tão complexos.

\section{NOTAS}

1. As igrejas evangélicas pentecostais surgiram nos Estados Unidos no início do século XX, em bairros negros. No Brasil, as primeiras igrejas pentecostais surgiram em 1910, quando foi criada a Congregação Cristã do Brasil, em São Paulo, e em seguida a Assembleia de Deus em 1911, em Belém no Pará. Essas igrejas se diferem das outras igrejas evangélicas protestantes, conhecidas como históricas ou tradicionais, por incorporarem aos seus cultos manifestações denominadas "dons do Espírito Santo" - experiências individuais marcadas pela emoção - como aqueles que, segundo o relato bíblico, teriam sido expressos pelos discípulos de Jesus, no Dia de Pentecostes (LIMA et al., 2003). Estes dons são de falar em línguas (glossolalia), de interpretação dessas línguas, de evangelização, de cura, de profecia, de sabedoria, de discernir os espíritos (ler os pensamentos) e de fazer milagres (CORTEN, 1996).

2. Por sua vez, o neopentecostalismo pode ser considerado um movimento religioso que surgiu em um período de grave crise econômica no Brasil, e foi liderado, principalmente, pela Igreja Universal do Reino de Deus, igreja esta criada no ano de 1977. Em seguida emergiram outras igrejas, tais como a Igreja Internacional da Graça de Deus em 1980 e a Igreja Cristo Vive em 1986. A partir desse período torna-se cada vez mais difícil quantificar o número de igrejas menores que têm surgido, principalmente em bairros de periferia e em comunidades (LIMA et al., 2003), disseminando-se nas faixas mais pobres da população. Essas igrejas caracterizam-se por utilizar os meios de comunicação de massa, enfatizam a prosperidade individual, a moralidade familiar e a prática do exorcismo de demônios (RAMALHO, 2000).

3. Gente Humilde. Composição: Garoto, Chico Buarque e Vinicius de Moraes.

4. Romaria. Composição: Renato Teixeira.

\section{Referências}

ALGEBAILE, E.B. Unidade entre pensamento e ação. Revista Brasileira de Educação. v. 14, n.42, p.585-587, 2009.

ARAÚJO, J.R.; FERREIRA, E.F.; ABREU, M.H.N.G. Revisão sistemática sobre estudos de espacialização da dengue no Brasil. Revista Brasileira de Epidemiologia, v. 1 1, n.4, p.696708, 2009.

BOFF, L. Pedagogia do oprimido e teologia da libertação. In: GADOTTI, M. (Ed.). 40 olhares sobre os 40 anos da pedagogia do oprimido. São Paulo: Editora e Livraria Instituto Paulo Freire, 2008. p.40.

BOFF, L. Ecologia social pobreza e miséria. Disponível em: <http://www.ecoterrabrasil.com.br>. Acesso em: $14 \mathrm{fev}$. 2005.

BRANDÃO, C. R. 40 anos de educação popular no Brasil e no mundo. In: ENCONTRO NACIONAL DE EDUCAÇÃO POPULAR EM SAÚDE, 2001, Brasília. Palestra.

BRANDÃO, C.R. Os deuses do povo: um estudo sobre a religião popular. Uberlândia: EDUDU, 2007.

BRICEÑO-LEON, R. Siete tesis sobre la educación sanitaria para la participación comunitária. Cadernos de Saúde Pública, v.1, n.12, p.7-30,1996.

CARVALHO, M.A.; ACIOLI, S.; STOTZ. E. O processo de construção compartilhada do conhecimento uma experiência de investigação científica do ponto de vista popular. In: VASCONCELLOS, E. A saúde nas palavras e nos gestos: reflexões da rede educação popular e saúde. São Paulo: Hucitec; 2001.

CARVALHO, M.A.P. Construção compartilhada do conhecimento: análise de material educativo. In: BRASIL. Ministério de Saúde. Caderno de educação popular e saúde. Brasilia: Ministério da Saúde, 2007. p.91-101. Série B. Textos Básicos de Saúde.

CESAR, W.; SHAULL, R. Pentecostalismo e futuro das igrejas cristãs: promessas e desafios. Petrópolis: Vozes, 1999.

CORAGGIO, J.L. Pesquisa urbana e projeto popular. Espaço e Debates, v.26, p.23-39, 1989. 
CORTEN, A. Os pobres e o espírito santo. Petrópolis: Vozes, 1996. 285 p.

DALGALARRONDO, P. Estudos sobre religião e saúde mental realizados no Brasil: histórico e perspectivas atuais. Revista de Psiquiatria Clínica, v.34, S.1, p.25-33, 2007.

DEMO, P. Pobreza da pobreza. Petrópolis: Vozes, 2003. 392 p.

FLEURI, R. Victor Valla e a pesquisa militante. Revista Brasileira de Educação. v. 14, n.42, p.579-583, 2009.

FREIRE, P. Pedagogia do oprimido. 17. ed. Rio de Janeiro: Ed. Paz e Terra, 1987.

GUERREIRO, S. Desafios atuais aos estudos das religiões. Comciência, maio 2005. Disponível em: <http://www. comciencia.br/reportagens/2005/05/13> Acesso em: 10/05/05

GUIMARÃES, M.B.L.; VALLA, V.V.; STOTZ, E.N. (Coords.). Os impasses da pobreza absoluta. Relatório da pesquisa vigilância civil da saúde na atenção básica. Rio de Janeiro: ENSP/FIOCRUZ, 2005.

LACERDA, A.; VALLA, V.V. Homeopatia e apoio social: repensando as práticas de integralidade na atenção e no cuidado à saúde. In: PINHEIRO, R.; MATTOS, R. Os sentidos da integralidade na atenção de no cuidado à saúde. Rio de Janeiro: UERJ, 2003.

LIMA, C.M.; VALLA, V.V. Religiosidade popular e saúde. In: Caderno de Educação Popular. Rio de Janeiro: CEPEL/ ENSP/FIOCRUZ, 2003.

LIMA, C.M.; VALLA, V.V. Religiosidade popular e saúde: fome de que? In: ENCONTRO NACIONAL DE PESQUISA EM EDUCAÇÃO EM CIÊNCIAS, 5., 2005, Bauru. Anais...

MACHADO, M.D. Carismáticos e pentecostais: adesão religiosa na esfera familiar. Campinas: Autores AssociadosANPOCS, 1996.

MARIZ, C. Alcoolismo, gênero e pentecostalismo. Religião e Sociedade, v.16, n.3, 1994.

MARTELETO, R.M.; VALLA, V.V. Informação e educação popular: o conhecimento social no campo da saúde. Perspectivas em Ciência e Informação, Belo Horizonte, ne, p.8-21, 2003.

MARTINS, J. A sociedade vista do abismo: novos estudos sobre exclusão, pobreza e classes sociais. Petrópolis: Vozes, 2002.

MARTINS, J.S. Dilemas sobre as classes subalternas na idade da razão. In: MARTINS, J.S. Caminhada no chão da noite. São Paulo: Hucitec, 1989.
MATTOS, R.A. A integralidade na prática (ou sobre a prática da integralidade). Cadernos de Saúde Pública, v.20, n.5, p.1411-1416, 2004.

MINAYO, M.C. Saúde-doença: uma concepção popular da etiologia. Cadernos de Saúde Pública, v.4, n.4, p.363-391, 1988.

MONTENEGRO, A.T. História oral e memória: a cultura popular revisitada. São Paulo: Contexto, 1992.

MORIN, E. A religação dos saberes: o desafio do século XXI. 3. ed. Rio de janeiro: Bertrand Brasil, 2002.

PAIVA, G.J. Ciência e religião: discursos nem sempre conflitantes. ComCiência, n.65, 2005. Disponível em: http:// www.comciencia.br/reportagens/2005/05/09.shtml. Acesso em: 10 maio 2005.

PARKER, C. Religião popular e modernização capitalista: outra lógica na América Latina. Petrópolis: Vozes, 1996.

RAMALHO, J. Desafios do pentecostalismo. Ensino Religioso, jun. 2000.

SCHWATZMAN, S. As causas da pobreza. Rio de Janeiro: FGV Editora, 2004. 208 p.

SILVA, L.C. . A participação das rezadeiras nos projetos de saúde comunitária do Estado da Paraíba. In: CONFERÊNCIA BRASILEIRA DE COMUNICAÇÃO E SAÚDE, 7., 2004, Olinda. Olinda: COMSAÚDE, 2004.

STOTZ, E.N. A educação popular nos movimentos sociais da saúde: uma análise de experiências nas décadas de 1970 e 1980. Trabalho, Educação e Saúde, v.3, n. 1, p.9-30, 2005.

STOTZ, E.N. et al. Janelas para o conhecimento. In: STOTZ, E.N.; MARTELETO, R.M. (Orgs.). Informação, saúde e redes sociais: diálogos de conhecimentos nas comunidades de Maré. Rio de Janeiro: Editora Fiocruz, 2009. 176p.

VALLA, V.V.; GUIMARÃES, M.B.L.; LACERDA, A. A qualidade do cuidado na convivência com os pobres: o trabalho dos pastores e dos agentes comunitários de saúde. In: PINHEIRO, R.; MATTOS, R.A. (Orgs.). Construção social da demanda. Rio de Janeiro: Abrasco, 2005. p.267-291.

VALLA, V.V. Participação popular e informação numa conjuntura de nova ordem mundial. In: MARTÍNEZ, F.J.M.; SILVA, L.R.; (Comps.) La medicina al final del milênio. Guadalajara: Universidad de Guadalajara, 1995.

VALLA, V.V. A crise da compreensão é nossa: procurando compreender a fala das classes populares. Educação e Realidade, v.22, n.2, 1997. 
VALLA, V.V.; STOTZ, E.N. (Orgs.). Educação saúde e cidadania. 2. ed. Petrópolis: Vozes, 1999.

VALLA, V.V. Procurando compreender a fala das classes populares. In: VALLA, V.V (Org.). Saúde e Educação. Rio de Janeiro: DP\&A, 2000.

VALLA, V.V. Globalização e saúde no Brasil: a busca da sobrevivência pelas classes populares via questão religiosa. In: VASCONCELLOS, E. (Org.). A saúde nas palavras e nos gestos. São Paulo: Hucitec, 2001.

VALLA, V.V. O que a saúde tem a ver com religião? In: VALLA, V.V (Org.). Religião e cultura popular. Rio de
Janeiro: DP\&A, 2001b.

VALLA, V.V. Pobreza, emoção e saúde: uma discussão sobre pentecostalismo e saúde no Brasil. Revista Brasileira de Educação, Campinas, n. 19, p.63-75, 2002.

VASCONCELLOS, E. Educação popular como instrumento de reorientação das estratégias de controle das doenças infecciosas e parasitárias. Cadernos de Saúde Pública, v.145, n.2, p.39-57, 1998.

VASCONCELLOS, E. A espiritualidade no cuidado e na educação e saúde. In: VASCONCELOS, E.M. (Org.). A espiritualidade no trabalho em saúde. São Paulo: Hucitec,2006.p.13-157. 